\title{
Pollen-Pistil Interaction among Certain Triploid Derivatives of Arachis Species
}

\author{
S. Saravanan* and L. Mahalingam \\ Tamil Nadu Agricultural University, Vriddhachalam, India \\ *Corresponding author
}

\section{Keywords \\ Pollen pisltil interaction, Wild groundnut, wide cross, Pollen attrition}

\section{Article Info}

Accepted:

05 April 2020

Available Online:

10 May 2020

\section{A B S T R A C T}

\begin{abstract}
The pollen tube growth in wide crosses involving Arachis hypogeae (var VRI 2, TMV 7 and TMV 13) and wild Arachis sp. (Arachis stenosperma, Arachis cruziana and Arachis kempmercadoi) have been interpreted among nine crosses. The wide crosses were monitored for pollen attrition and pollen proliferation, being construed that greater levels of genetic distance trigger larger quantum of physiological and physical alterations at various levels of pistil growth. Pollen germination administered greater effect among wide crosses battling poor penetration of pollen tube in the transmitting tissue. The rate of pollen tube proliferation among wide crosses at different levels of pistils was found significant at initial level than at the later stages. The counts of pollen tubes growing down the style were recorded in all the treatment over different level of pistils. The pattern of reduction of tubes at different levels of pistils was very similar for all the crosses. The significantly higher level in proliferation of pollen tubes was noticed in the cross TMV 7 x Arachis stenosperma) as 39.50 per cent and is followed by the cross VRI $2 \times$ Arachis kempmercadoi (35.25 per cent). The crosses, VRI 2 x Arachis stenosperma, TMV 13 x Arachis stenosperma and TMV 13 x Arachis cruziana exhibited significantly lower value of pollen tube proliferation at different levels of pistils. The failure of pollen tube to reach and fertilize the ovule is given by pollen attrition. Stylar attrition reported to be maximum in the cross VRI 2 x Arachis stenosperma while is low in the crosses, VRI 2 x Arachis kempfmercadoi, TMV 13 x Arachis kempfmercadoi and TMV $7 \mathrm{x}$ Arachis stenosperma. It was evidenced that significant reduction in density of pollen tubes observed as they grow along the style. Also, the studies on genetic system of pollen pistil interaction construe more obvious in the upper part of the style than in the lower half delivering unique physical or physiological confronts impacting significant negative interaction over genetic systems of the gametophytes.
\end{abstract}

\section{Introduction}

Post pollination processes in plants always triggered by the attitude of inter and intra sexual mechanism adopted. In plants, judicious counts of sex gametophytes generated during the gametophytic phase. Nevertheless, part of lesser numbers of female gametophytes attains successful fertilization. Pollen grains on compatible stigma germinate and produce a pollen tube from which the sperm cells are migrated to the female gametophyte through the pollen tube transmitting tissue holding indiscriminate territory between stigma and ovary.

Pollen attrition prelude compatible action thereby targets productive number of ovules than that of seeds (Saravanan, 2017). The greater the pollen source, the higher the seed 
set, seed germination and seedling vigor while also the pollen thickness increased upon the length of exposure to pollinators varying with time to time and from population to population (Lankinen et al., 2018). Pollen density along with thickness always adjudged to stimulate positive interaction between pollen and stigma. The pollen competition is eventually a result of pollen loads on the stigma. (Zheng et al., 2018). Erstwhile, rate of deposition of pollen grains on stigma exceeds the ovule production for fertilization (Bedinger et al., 2017).

Anyhow, the candidate genes ultimately resolve the unifying or integrating several steps constituting successful fertilization of embryo. Further, elusive molecular characterization after triggering genetic diversity could aid fruitful for proven and desirable crop improvement (Rajendra Kumar et al., 2017). In Arachis, seeds per pod are highly interfered by the pollen competition along with the vigour of the resultant sporophyte. The pollen tubes have been appraised to follow a fixed pattern of reduction since the initial number of pollen tubes is progressively reduced along the style. Reduced growth of pollen tube might have resulted through an interaction effect of pollen and style interaction. Therefore, integrative steps involved in the interaction of pollen and pistil plays an effusive role during fusion of the sex gametes.

\section{Materials and Methods}

The study was made using multiple sets of wide crosses at Regional Research Station, Vriddhachalam. The treatment involved in the dusting of different loads of pollen from different sets of diploid Arachis species ( Arachis stenosperma and Arachis kempmercadoi) to stigma of tetraploid Arachis hypogaea (var VRI 2, TMV 7 and TMV 13) parent. Flowers were collected at time of anthesis and rubbed over the stigma of female parent that had been emasculated at previous day by removing the anthers and petals to make them unattractive to insects (Veerappan et al., 2014).

Among the crosses, five pistils were collected and fixed in formalin: acetic acid: ethanol in the ratio of $1: 1: 18$. After 3 days after pollination, when the pollen tube growth might have reached the base of the style, the pistils were fixed in the fixative. From squash preparation of pistils washed in distilled water, the pollen tube growth along the style was monitored after the pistils have boiled in 5 per cent sodium sulphate to soften tissues and stained with 0.1 per cent aniline blue in $0.1 \mathrm{~N} \mathrm{~K}_{3} \mathrm{PO}_{4}$ (Geetha and Jayaraman, 2000 and Geetha et al., 2004).

The pre-treated pistils were kept under Nikon microphot-Fx microscope with fluorescence attachment, illuminated with 200w high pressure UV lamp for examination. The observations were taken with B (380-490nm) and or BG $(650 \mathrm{~nm})$ excitation filters in combination with BA 520 or BA 530 barrier filter. Colour photographs were taken either with barrier filter (greenish yellow) or without barrier filter (blue background with bright white fluorescing pollen tube). Data were analyzed in completely randomized design and treatment means were compared with Duncans Multiple Range Test.

\section{Results and Discussion}

The proportionate interpretation on key phenological traits of parents and triploid derivatives of Arachis was given in Table 1. Progenies of different genetic nature construed significant variations in habit, leaf texture, leaf shape, bract shape, bract size, length of staminal column and pollen fertility. The compatibility mechanism among the wide crosses is adjudged through perturbation of 
pollen germination, pollen tube growth and fertilization which are determined by fluorescence microscopy. The fluorescence microscopic technique involve pistils getting stained with aniline blue and better viewed under ultra violet illumination. The callose plugs present in the pollen tube fluoresce brightly thereby the pollen tube can be clearly interpreted in the stylar tissue and documented. Further insufficient softening of pistils leaves the specimen hardy and difficult to observe the pollen tube growth due to differential refraction. Moreover, also the over softening may result in breakage of pistils during gentle press and render the observation of pollen tube faulty. The softening of the pistils of diploid parents was optimum at $12 \mathrm{~N}$ and $10 \mathrm{~N} \mathrm{NaOH}$ for 6 and 8 hours duration respectively, besides the tetraploids had $10 \mathrm{~N} \mathrm{NaOH}$ for 6 hours duration as optimum. The optimum staining and better fluorescence was obtained when 0.25 per cent aniline blue was dissolved in $0.1 \mathrm{~N} \mathrm{~K}_{3} \mathrm{PO}_{4}$ and kept for 6 hours.

The studies were made on the few wide crosses of Arachis to interrogate the knock of alien pollen on stigma for reviving the fertilization barriers attributed in coordination with pollen germination and its walk on stigma of alien species. Congregate of alien pollen from wild Arachis species upon Arachis hypogeae recorded poor pollen fertility and germination values compared to parental genotypes (Table 1).

Different forms of distant crosses offered varied proportions of pollen deposition. The wide crosses, VRI 2 x Arachis kempfmercadoi and TMV 7 x kempfmercadoi recorded higher pollen germination of 38 and 34 per cent respectively. The activity of pollen over the stigma and style of female plant offered scope for interpretation of pollen attrition. Significant variation on growth of pollen grains over the stigma pertaining to different crosses deliberated uneven penetration of pollen tubes over the transmitting tissue along the first half of the stylar canal. This observable variation of pollen tube spread on transmitting tissue of stylar canal registered significantly higher at initial level compared to the later stage of stylar penetration. The gradual reduction in density of pollen tube growing through the stylar canal was observed among all crosses spreading over different levels of pistils.

The significantly higher level in proliferation of pollen tubes was noticed in the cross VRI 2 $\mathrm{x}$ Arachis kempfmercadoi as 41.31 per cent and is followed by the cross TMV $7 \mathrm{x}$ kempfmercadoi (37.65 per cent). VRI $2 \mathrm{x}$ Arachis stenosperma (23.69 per cent), TMV 13 x Arachis stenosperma (26.25 per cent) and TMV 13 x Arachis cruziana (29.48 per cent) exhibited significantly lower value of pollen tube proliferation at different levels of pistils (Table 3). Stylar attrition was determined from the pollen tube not reaching the ovary. Stylar attrition was minimum in the crosses VRI 2 x Arachis kempfmercadoi (58.69 per cent) and TMV 7 x Arachis kempfmercadoi (62.35 per cent) while VRI 2 $\mathrm{x}$ Arachis cruziana (76.20 per cent) and TMV 7 x Arachis cruziana (73.84 per cent) registered the maximum (Table 4). A dramatic diminution in the pollen tube density along the stylar canal was adjudged.

The data signified the proportionate decrease in pollen tube in the stylar region as compared to opening number of pollen tube at the mouth of stylar canal. This further evidenced the impartial decrease in density of pollen tube all along the stylar region suggesting the possibility of genetic interactions on regulation of pollen tube attrition (Regel, 2019). The greater decrease in pollen tube number at mid stylar region could enhance alarming probability of pollen attrition (Table $3)$. 
Table.1 Morphological dissection of triploids

\begin{tabular}{|c|c|c|c|c|c|c|c|}
\hline Pedigree & $\begin{array}{c}\text { Length of } \\
\text { Primary } \\
\text { branch }(\mathbf{c m})\end{array}$ & $\begin{array}{l}\text { Length of } \\
\text { Secondary } \\
\text { Branch } \\
\text { (cm) }\end{array}$ & $\begin{array}{l}\text { Leaf } \\
\text { Area } \\
\left(\mathrm{cm}^{2}\right)\end{array}$ & $\begin{array}{c}\text { Length } \\
\text { of calyx } \\
\text { tube } \\
\text { (cm) }\end{array}$ & $\begin{array}{l}\text { Length of } \\
\text { Standard } \\
\text { petal } \\
\text { (cm) }\end{array}$ & $\begin{array}{l}\text { Width of } \\
\text { Standard } \\
\text { petal } \\
\text { (cm) }\end{array}$ & Leaflet colour \\
\hline VRI 2 x Arachis kempffmercadoi & 41 & 60 & 9.03 & 5.20 & 1.32 & 1.67 & Light Green \\
\hline VRI 2 x Arachis cruziana & 40 & 61 & 8.40 & 5.30 & 1.31 & 1.64 & Light Green \\
\hline VRI 2 x Arachis stenosperma & 40 & 58 & 7.79 & 5.00 & 1.29 & 1.69 & Light Green \\
\hline TMV 7 x Arachis stenosperma & 39 & 62 & 10.08 & 5.20 & 1.28 & 1.58 & Light Green \\
\hline $\begin{array}{l}\text { TMV } 7 \text { x Arachis } \\
\text { kempffmercadoi }\end{array}$ & 40 & 61 & 8.20 & 5.00 & 1.32 & 1.60 & Light Green \\
\hline TMV 7 x Arachis cruziana & 40 & 60 & 9.89 & 5.20 & 1.31 & 1.55 & Light Green \\
\hline TMV $13 \times$ Arachis stenosperma & 37 & 59 & 8.40 & 5.40 & 1.27 & 1.60 & Dark green \\
\hline $\begin{array}{l}\text { TMV } 13 \times \text { Arachis } \\
\text { kempffmercadoi }\end{array}$ & 39 & 58 & 8.17 & 5.30 & 1.29 & 1.57 & Dark green \\
\hline TMV 13 x Arachis cruziana & 42 & 60 & 9.66 & 5.10 & 1.30 & 1.56 & Dark green \\
\hline VRI 2 & 45 & 58 & 8.30 & 5.64 & 1.40 & 1.77 & Light green \\
\hline TMV 7 & 42 & 59 & 7.82 & 5.42 & 1.39 & 1.69 & Light Green \\
\hline TMV 13 & 44 & 57 & 8.30 & 5.70 & 1.35 & 1.60 & Dark Green \\
\hline Arachis cruziana & 38 & 60 & 8.52 & 5.30 & 1.20 & 1.30 & Light Green \\
\hline Arachis stenosperma & 36 & 61 & 7.52 & 5.10 & 1.22 & 1.32 & Light Green \\
\hline Arachis kempffmercadoi & 37 & 62 & 7.88 & 5.25 & 1.18 & 1.28 & Light Green \\
\hline
\end{tabular}

Table.2 Proportion mean \pm SE of pollen grain deposition over stigma

\begin{tabular}{|l|c|c|c|}
\hline \multicolumn{1}{|c|}{ Treatment } & $\begin{array}{c}\text { Pollen } \\
\text { grains in } \\
\text { stigma }\end{array}$ & $\begin{array}{c}\text { Germinated } \\
\text { pollen grain }\end{array}$ & $\begin{array}{c}\text { Per cent of pollen } \\
\text { germination }\end{array}$ \\
\hline VRI 2 x Arachis stenosperma & $1354^{\mathrm{cd}}$ & $325^{\mathrm{d}}$ & $\mathbf{2 4}^{\mathrm{d}}$ \\
\hline TMV 7 x Arachis stenosperma & $865^{\mathrm{ef}}$ & $225^{\mathrm{e}}$ & $\mathbf{2 6}^{\mathrm{d}}$ \\
\hline TMV 13 x Arachis stenosperma & $1481^{\mathrm{c}}$ & $400^{\mathrm{cd}}$ & $\mathbf{2 7}^{\text {cd }}$ \\
\hline VRI 2 x Arachis cruziana & $740^{\mathrm{g}}$ & $288^{\mathrm{de}}$ & $\mathbf{2 0}^{\mathrm{bc}}$ \\
\hline TMV 7 x Arachis cruziana & $820^{\mathrm{f}}$ & $250^{\mathrm{de}}$ & $\mathbf{2 5}^{\mathrm{d}}$ \\
\hline TMV 13 x Arachis cruziana & $795^{\mathrm{g}}$ & $220^{\mathrm{e}}$ & $\mathbf{2 2}^{\mathrm{c}}$ \\
\hline VRI 2 x Arachis kempffmercadoi & $802^{\mathrm{f}}$ & $305^{\mathrm{de}}$ & $\mathbf{3 8}^{\mathrm{c}}$ \\
\hline TMV 7 x Arachis kempffmercadoi & $1250^{\mathrm{d}}$ & $425^{\mathrm{c}}$ & $\mathbf{3 4}^{\mathbf{c}}$ \\
\hline TMV 13 x Arachis kempffmercadoi & $990^{\mathrm{e}}$ & $325^{\mathrm{d}}$ & $\mathbf{2 4}^{\mathrm{d}}$ \\
\hline VRI 2 & $1680^{\mathrm{b}}$ & $1124^{\mathrm{ab}}$ & $\mathbf{6 7}^{\mathrm{ab}}$ \\
\hline TMV 7 & $1845^{\mathrm{a}}$ & $1352^{\mathrm{a}}$ & $\mathbf{7 3}^{\mathrm{a}}$ \\
\hline TMV 13 & $1695^{\mathrm{b}}$ & $980^{\mathrm{b}}$ & $\mathbf{5 8}^{\mathbf{b}}$ \\
\hline Arachis stenosperma & $954^{\mathrm{e}}$ & $440^{\mathrm{c}}$ & $\mathbf{4 6}^{\mathbf{b c}}$ \\
\hline Arachis cruziana & $658^{\mathrm{gh}}$ & $215^{\mathrm{e}}$ & $\mathbf{3 3}^{\mathrm{c}}$ \\
\hline Arachis kempffmercadoi & $\mathbf{8 2 1}^{\mathrm{ef}}$ & $\mathbf{3 2 4}^{\mathrm{d}}$ & $\mathbf{3 9}^{\mathbf{c}}$ \\
\hline
\end{tabular}

Means followed by a common letter are not significantly different at 5 per cent by DMRT 
Table.3 Mean \pm SE of pollen tubes at different levels of pistil

\begin{tabular}{|c|c|c|c|c|c|c|c|}
\hline \multirow[t]{2}{*}{ Treatment } & \multicolumn{6}{|c|}{ Pistil level } & \multirow{2}{*}{$\begin{array}{l}\text { Per cent } \\
\text { Pollen tube } \\
\text { survival }\end{array}$} \\
\hline & Stigma & $\begin{array}{c}\text { Transmitting } \\
\text { tissue }\end{array}$ & $1 / 4$ style & $1 / 2$ style & $3 / 4$ style & Ovary & \\
\hline VRI 2 x Arachis stenosperma & $325 \pm 5.70$ & $121 \pm 2.12$ & $111 \pm 1.94$ & $100 \pm 1.94$ & $87 \pm 1.52$ & $77 \pm 1.36$ & 23.69 \\
\hline TMV 7 x Arachis stenosperma & $225 \pm 3.95$ & $142 \pm 2.49$ & $130 \pm 2.28$ & $118 \pm 2.28$ & $102 \pm 1.79$ & $82 \pm 1.44$ & 36.44 \\
\hline TMV 13 x Arachis stenosperma & $400 \pm 7.02$ & $163 \pm 2.87$ & $150 \pm 2.62$ & $136 \pm 2.62$ & $117 \pm 2.06$ & $105 \pm 1.84$ & 26.25 \\
\hline VRI $2 \times$ Arachis cruziana & $295 \pm 5.25$ & $135 \pm 2.37$ & $120 \pm 2.33$ & $108 \pm 1.89$ & $102 \pm 1.78$ & $99 \pm 1.60$ & 33.56 \\
\hline TMV 7 x Arachis cruziana & $288 \pm 4.35$ & $115 \pm 2.20$ & $98 \pm 1.70$ & $91 \pm 1.56$ & $88 \pm 1.54$ & $80 \pm 1.40$ & 33.33 \\
\hline TMV 13 x Arachis cruziana & $250 \pm 4.52$ & $132 \pm 2.30$ & $95 \pm 1.65$ & $87 \pm 1.51$ & $82 \pm 1.43$ & $79 \pm 1.33$ & 29.48 \\
\hline VRI 2 x Arachis kempfmercadoi & $220 \pm 5.35$ & $160 \pm 2.81$ & $152 \pm 2.67$ & $138 \pm 2.42$ & $131 \pm 2.30$ & $126 \pm 2.21$ & 41.31 \\
\hline TMV 7 x Arachis kempfmercadoi & $425 \pm 7.46$ & $192 \pm 3.37$ & $184 \pm 3.23$ & $170 \pm 2.98$ & $164 \pm 2.88$ & $160 \pm 2.81$ & 37.65 \\
\hline TMV 13 x Arachis kempfmercadoi & $325 \pm 5.69$ & $137 \pm 2.40$ & $130 \pm 2.40$ & $118 \pm 2.06$ & $103 \pm 1.81$ & $84 \pm 1.47$ & 32.70 \\
\hline VRI 2 & $1124 \pm 19.72$ & $1085 \pm 19.04$ & $1002 \pm 17.58$ & $992 \pm 17.41$ & $968 \pm 16.99$ & $952 \pm 16.70$ & 84.70 \\
\hline TMV 7 & $1352 \pm 23.72$ & $1286 \pm 22.57$ & $1229 \pm 21.57$ & $1209 \pm 21.21$ & $1189 \pm 20.86$ & $1156 \pm 20.28$ & $\mathbf{8 5 . 5 0}$ \\
\hline TMV 13 & $980 \pm 17.20$ & $895 \pm 15.70$ & $821 \pm 14.41$ & $796 \pm 13.97$ & $728 \pm 12.77$ & $702 \pm 12.32$ & 71.63 \\
\hline Arachis stenosperma & $440 \pm 7.72$ & $385 \pm 6.76$ & $317 \pm 5.56$ & $296 \pm 5.19$ & $256 \pm 4.49$ & $240 \pm 4.21$ & $\mathbf{5 4 . 5 5}$ \\
\hline Arachis cruziana & $324 \pm 5.69$ & $250 \pm 4.39$ & $194 \pm 3.40$ & $159 \pm 2.79$ & $144 \pm 2.53$ & $132 \pm 2.32$ & 40.74 \\
\hline Arachis kempfmercadoi & $405 \pm 7.12$ & $365 \pm 6.40$ & $320 \pm 5.62$ & $260 \pm 4.85$ & $235 \pm 4.40$ & $205 \pm 3.85$ & 50.62 \\
\hline
\end{tabular}

Means followed by a common letter are not significantly different at 5 per cent by DMRT 
Table.4 Pollen attrition per cent for different wide crosses

\begin{tabular}{|l|c|c|c|}
\hline \multicolumn{1}{|c|}{ Treatment } & $\begin{array}{c}\text { Pistil } \\
\text { distribution over } \\
\text { stigmatic surface }\end{array}$ & $\begin{array}{c}\text { Pistil } \\
\text { distribution } \\
\text { inside ovary }\end{array}$ & Pollen attrition \\
\hline VRI 2 x Arachis stenosperma & $325^{\mathrm{d}}$ & $77^{\mathrm{gh}}$ & $\mathbf{7 6 . 2 0}$ \\
\hline TMV 7 x Arachis stenosperma & $225^{\mathrm{e}}$ & $91^{\mathrm{f}}$ & $\mathbf{6 3 . 5 6}$ \\
\hline TMV 13 x Arachis stenosperma & $400^{\mathrm{cd}}$ & $105^{\mathrm{de}}$ & $\mathbf{7 3 . 8 4}$ \\
\hline VRI 2 x Arachis cruziana & $295^{\mathrm{de}}$ & $99^{\mathrm{f}}$ & $\mathbf{6 6 . 4 4}$ \\
\hline TMV 7 x Arachis cruziana & $240^{\mathrm{ef}}$ & $80^{\mathrm{fg}}$ & $\mathbf{6 6 . 6 7}$ \\
\hline TMV 13 x Arachis cruziana & $268^{\mathrm{e}}$ & $79^{\mathrm{fg}}$ & $\mathbf{7 0 . 5 2}$ \\
\hline VRI 2 x Arachis kempfmercadoi & $305^{\mathrm{de}}$ & $126^{\mathrm{d}}$ & $\mathbf{5 8 . 6 9}$ \\
\hline TMV 7 x Arachis kempfmercadoi & $425^{\mathrm{c}}$ & $160^{\mathrm{d}}$ & $\mathbf{6 2 . 3 5}$ \\
\hline TMV 13 x Arachis kempfmercadoi & $315^{\mathrm{d}}$ & $84^{\mathrm{f}}$ & $\mathbf{7 3 . 3 3}$ \\
\hline VRI 2 & $1124^{\mathrm{ab}}$ & $952^{\mathrm{ab}}$ & $\mathbf{1 5 . 3 0}$ \\
\hline TMV 7 & $1352^{\mathrm{a}}$ & $1156^{\mathrm{a}}$ & $\mathbf{1 4 . 5 0}$ \\
\hline TMV 13 & $980^{\mathrm{b}}$ & $702^{\mathrm{b}}$ & $\mathbf{2 8 . 3 7}$ \\
\hline Arachis stenosperma & $440^{\mathrm{c}}$ & $240^{\mathrm{c}}$ & $\mathbf{4 5 . 4 5}$ \\
\hline Arachis cruziana & $324^{\mathrm{d}}$ & $132^{\mathrm{d}}$ & $\mathbf{5 9 . 2 6}$ \\
\hline Arachis kempfmercadoi & $\mathbf{4 0 5}^{\mathrm{cd}}$ & $\mathbf{2 0 5}^{\mathrm{c}}$ & $\mathbf{4 9 . 3 8}$ \\
\hline
\end{tabular}

Means followed by a common letter are not significantly different at 5 per cent by DMRT

The same results were also reported by Subramanian and Muthiah (2000), Abdelgadir et al., (2012), Pandey et al., (2009) in redgram and Saravanan (2017) in Groundnut. Mazer et al., (2016) concluded pollen attrition was dictated by style length that influences the rate of pollen grain germination via stigma clogging or pollen-pollen interactions.

Reports on higher rate of pollen tube attrition in the terminal part of the pistil as pronounced by Cruzan (1989) besides the variation in pollen tube density in the stylar canal pointed by Hormaza and Herrero (1996) and Choudary et al., (2015).

Also it was adjudged the independency of germinating pollen grains on the stigma in the lower part of the pistil. In the present study also, the superimposition of pollen pistil interaction on genetic nature could attribute stylar inhibition of pollen attrition on the stylar region as substantiated by Bedingar et al., (2017). However, the parental cultures exhibited admissible pollen germination and pollen tube growth attributing better seed set besides the tetraploid groundnut shown highest pollen tube proliferations. To conclude, among wide crosses, poor pollen germination lead unprivileged pollen tube proliferations at varied regions of pistils eventually lead to reduced seed set.

\section{References}

Abdelgadir, H. A. S.D. Johnson, J. Van Staden. 2012. Pollen viability, pollen germination and pollen tube growth in the biofuel seed crop Jatropha curcas (Euphorbiaceae). South African Journal of Botany. 79:132139.

Bedinger, P. A., A.K. Broz, A. Tovar-Mendez and B. McClure. 2017. Pollen-Pistil Interactions and Their Role in Mate Selection. Plant physiology, 173(1), 79-90.

Charlotte Beckford, Montana Ferita, Julie Fucarino. 201). An Agent-based Model of 
Pollen Competition in Arabidopsis thaliana. valpo.edu.

Cruzan, M.B. 1989. Pollen tube distribution in Nicotiana glauca: evidence for density dependent growth. Am. J. Bot. 73:902-907.

Geetha, K. and N. Jayaraman. (2000). Pollen germination and pollen tube growth studies in in vitro in maize. Ind. J. Agrl. Res. 34(3):206-208.

Geetha, K., Vijayabaskaran and N. Jayaraman. 2004. In vitro studies on pollen germination and pollen tube growth in maize. Food, Agriculture \& Environment Journal, 2 (1): 57-62

Heslop-Harrison Y. 2000. Control gates and micro-ecology: the pollen-stigma interaction in perspective. Ann Bot. 85:5-13.

Hodnett G. L., B.L. Burson, W. L., Rooney, S. L., Dillon and H.J. Price. 2005. Pollen-Pistil interactions result in reproductive isolation between Sorghum bicolor and divergent Sorghum species. Crop Sci. 45:1403-1409

Lankinen, Å., S. Lindström, T. D'Hertefeldt. 2018. Variable pollen viability and effects of pollen load size on components of seed set in cultivars and feral populations of oilseed rape. PloS one, 13(9), e0204407. https://doi.org/10.1371/journal.pone.020440 7

Mazer S.J., A.K. Moghaddasi, A.K. Bello and A.A.Hove. 2016. Winning in style: Longer styles receive more pollen, but style length does not affect pollen attrition in wild Clarkia populations. Am J Bot. 103(3):408422.

Mulcahy, G. B. and D.L. Mulcahy. 1983. A comparison of pollen tube growth in bi and tri nucleate pollen. In: Mulcahy D.L.and E. Ottaviano (eds) pollen:biology and implications for plant breeding. Elsevier, New York, pp:29-33.

Pandey, N., G.C. Pathak and C.P. Sharma. 2009. Impairment in reproductive development is a major factor limiting seed yield of black gram under zinc deficiency. Biol. Plant. 53:723-727.

Rajendra Kumar, Renu Yadav, Sangeeta Soi, Srinivasan, S.S.Yadav, Ashwani Yadav, J.P.Mishra, Neha Mittal, Neelam Yadav, Ashwani Kumar, Vaishali, Hemant Yadav and Hari D Upadhyaya. 2017. Morphomolecular characterization of landraces/wild genotypes of Cicer for Biotic/ Abiotic stresses. Legume Research.40: 974-984.

Regel, C. E. 2019. The Incidence and Implications of Mate Diversity in Seed Plants (Unpublished master's thesis). University of Calgary, Calgary, AB. http://hdl.handle.net/1880/110890 master thesis.

Saravanan, S. 2017. Palynological behavior among wide crosses of Arachis species under diverse growth systems. The Bioscan, 12(3): 1553-1556.

Souto, P. C., M.A. Aizen and A.C. Premoli. 2002. Effects of crossing distance and genetic relatedness on pollen performance in Alstroemeria aurea (Alstroemeriaceae). Am. J. Bot. 89:427-432.

Subramanian, A and A.R. Muthiah. 2000. Studies on incompatibility barriers operating in crosses between Vigna mungo (L.) Hepper and Vigna radiata (L.) Wilczek. Legume Research 24(2): 87-91.

Veerappan, V., K. Kadel, N.Alexis, A. Scott, I. Kryvoruchko, S. Sinharoy, M. Taylor, M. Udvardi, and R. Dickstein. 2014. Keel petal incision: a simple and efficient method for genetic crossing in Medicago truncatula. Plant Methods. 10: 1-10

Zhang, C., G. Li and T. Chen. 2018. Heat stress induces spikelet sterility in rice at anthesis through inhibition of pollen tube elongation interfering with auxin homeostasis in pollinated pistils. Rice 11, 14 .

\section{How to cite this article:}

Saravanan. S. and Mahalingam. L. 2020. Pollen-Pistil Interaction among Certain Triploid Derivatives of Arachis Species. Int.J.Curr.Microbiol.App.Sci. 9(05): 370-376. doi: https://doi.org/10.20546/ijcmas.2020.905.042 